\title{
Financial burden of survivors of medically- managed myocardial infarction and its association with selected social determinants and quality of life in a lower middle income country
}

\author{
P. K. B. Mahesh ${ }^{1 *}$ (D, M. W. Gunathunga ${ }^{2}$, S. Jayasinghe ${ }^{3}$, S. M. Arnold', D. S. V. Mallawarachchi ${ }^{4}$, S. K. Perera ${ }^{5}$ \\ and U. A. D. Wijesinghe ${ }^{6}$
}

\begin{abstract}
Background: Burden from ischemic heart disease is rising in Sri Lanka due to the demographic and epidemiological transitions. Documented literature is scarce on quality of life, financial burden and its determinants in relation to myocardial infarction (MI). This study was done to describe the financial burden among the survivors of MI managed only with drugs (i.e. those who did not undergo Percutaneous Coronary Intervention or Coronary Artery Bypass Graft) and its association with selected social determinants (SDHs) and quality of life (QOL).

Methods: A cross sectional study was done among Ml survivors in 13 hospitals in the premier province of Sri Lanka. Out of 336 participants recruited at hospital stay, 270 responded through a self-administered questionnaire at 1 month post discharge. Questionnaire included sections on financial burden, selected SDHs and on QOL measured by the EQ-5D-3 L QOL tool. Presence of financial burden was determined using an operational definition. Associations were tested with Mann-Whitney-U test, Chi square test and Spearman-correlation-coefficient at 5\% significant level.

Results: Around 40\% ( $n=116)$ had to seek financial support for out-of-pocket expenditure. Nearly 5\% $(n=6)$ of previously employed participants had lost their job. Of the employed respondents ( $n=139,51.5 \%), 29 \%(n=85)$ had limited physical activity and $40 \%(n=115)$ had limitations of employment time. Of the respondents, $15.4 \%$ had to apply for a loan, $7.8 \%$ had to sell a property, $19.1 \%$ had an income loss and $33.8 \%$ had to restrict usual expenses. Financial burden was not significantly associated with gender $(p=0.146)$, ethnicity $(p=0.068)$, highest education $(p=0.184)$ and area of residence $(p=0.369)$. Influence of income $(p=0.001)$, social support $(p=0.002)$ and the health infrastructure $(p<0.001)$ were significantly associated with the occurrence of a financial burden. In the group with a financial burden, the index score $(p=0.002)$ and VAS score $(p<0.001)$ of EQ-5D-3 $L$ were significantly lower.

Conclusions: Financial burden is common among survivors of medically-managed occurring irrespective of the gender, ethnicity, education and the area. It is influenced significantly by the income, level of social support and the level of health infrastructure. The financial burden is influencing the post-discharge-1-month QOL.
\end{abstract}

Keywords: Myocardial infarction, financial burden, Quality of life, Social Determinants of Health, EQ-5D-3 L, STEMI, NSTEMI

\footnotetext{
* Correspondence: buddhikamaheshpk@gmail.com;

rdhs.cb@healthdept.wp.gov.lk

${ }^{1}$ Office of Regional Director of Health Services, Colombo, Sri Lanka

Full list of author information is available at the end of the article
} 


\section{Background}

Chronic Non Communicable Diseases (NCDs) impose a severe threat for lower and middle income countries with Sri Lanka being a no exception [1-3]. Cardiovascular diseases are a category with high global disease burden falling under the chronic NCDs [4-6]. Among cardiovascular diseases, myocardial infarction (MI) is a main acute critical events endangering the lives of affected people and decreasing the quality of life [7-9].

It has been shown that chronic NCDs potentially make all people vulnerable to a financial risk and this risk is more in poorer people [2,10-12]. The magnitude of Catastrophic Health Expenditure (CHE) is significantly associated with many social factors $[13,14]$. It is acknowledged that health cannot be improved without addressing the Social Determinants of Health (SDHs) [15]. The WHO Commission on Social Determinants of Health $(\mathrm{CSDH})$ has introduced the CSDH conceptual framework for action on SDHs [14, 16].

Literature from the South Asian region shows that, in some occasions a significant amount of total household expenditure is spent for healthcare payments [3, 10, 17]. Making the situation worse, when a critical event is experienced on top of chronic NCDs, more financial burden is resulted. In relation to critical illnesses, the similar findings have been highlighted in the global literature [18-22].

In MI, patients are managed as in-ward patients and are later followed up at out-patient ambulatory clinics. Even though the state services provide free-of-charge care in Sri Lanka, there are instances patients have to experience out-of-pocket expenditure and indirect costs [2]. When concomitant comorbid conditions are found the financial burden for concomitant coronary heart disease is even higher [13].

Exploring the financial burden of the survivors of MI provides the true scenario on aspects like equity in healthcare. The evaluation of the associations between SDHs with the financial burden, provide scientific hints for the prioritization of families that need potential financial support. Furthermore the evaluation of the association of the financial burden with QOL would reveal the impact of the disease on their lifestyle as a whole. In relation to the association between financial burden and social determinants, comprehensive literature is not commonly found globally [23]. In relation to the lower middle income countries like Sri Lanka, the documented literature on these aspects is rarer. This study was done to bridge this gap with the aim of describing the financial burden faced by the survivors of MI who were medically managed [i.e. without Percutaneous Coronary Intervention (PCI) or Coronary Artery Bypass Graft $(\mathrm{CABG})]$ and its association with selected social determinants and quality of life.

\section{Methods}

The study included two cross sectional data collections in 13 government hospitals, in the Western Province of Sri Lanka. Study population included the patients who were admitted to the above settings with the diagnosis of MI. Inclusion criteria included the criteria for the diagnosis of MI Category A of the 2008-2009 revisions of the World Health Organization's diagnostic criteria [24]. These included: at least one value of increased level of cardiac biomarkers (preferably troponin) with at least one of the following; development of pathological $Q$ waves, symptoms of ischemia, ECG changes (new ST-T changes or new left bundle branch block) and imaging evidence [24]. The demarcation of STEMI and NSTEMI were done based on European Society for Cardiology guidelines [25]. Participants with duration of stay less than $48 \mathrm{~h}$, participants who underwent invasive interventions (i.e. PCI or CABG) and with known pre-MI physical or mental disabilities which would potentially reduce the quality of life were excluded.

All patients who satisfy the above criteria who were admitted to the mentioned 13 settings within the Western province were selected as eligible for the study. Sample size was calculated with the formula $n=z^{2} \times p(1-p)^{2} /$ $\mathrm{d}^{2}$ getting the expected prevalence of financial burden based on documented literature [20, 21, 23, 26]. It was calculated that a minimal number of 235 records would be needed at data analysis stage. With an assumed response rate of $70 \%$, the minimum sample size needed to be recruited at the data collection stage was 336 . Data collection started simultaneously in all the study settings on 1st of January 2015 and continued until the sample size was in March 2015.

Data collection was done by the investigators and seven trained data collectors who were medically qualified graduates prior to their medical internship. Data collectors daily visited the medical wards that were respectively allocated to them out of the study settings. They verified the inclusion criteria of the patients who had been diagnosed with MI by the ward staff. A selfadministered questionnaire was given to the participants with a stamped envelope addressed to the principal investigator. The contact details were obtained and a reminder was given at the completion of 28 days.

The questionnaire consisted of three sections; data on the post-discharge 1 month QOL, financial burden and the social determinants. The post-discharge 1-month QOL was assessed using the EQ-5D-3 L generic QOL tool. The financial burden section included the questions formed with the literature review and expert guidance. The questions were based on the operational definition of "a situation in which the participant has experienced an actual or potential financial loss and is worried about it". Four structural SDHs (i.e. gender, ethnicity, income 
and highest education level) and three intermediate SDHs (place of living, social support and level of health infrastructure) were selected as contextually relevant and as influencing the financial burden $[15,16]$.

Gender, Ethnicity and residence were coded as categorical variables. Place of living was categorized as "urban" or "rural" according to the "concepts and definitions" of the department of census and statistics [27]. Income, highest educational level, level of social support and health infrastructure were noted as quantitative variables. For measuring the social support a modified tool was used with a maximum score of 10 , based on the set of questions used by Mallawarachchi in 2007 (Table 1) [28, 29].

Following literature review and expert opinions, a judgmentally validated tool was used for quantifying the level of health infrastructure with a maximum score of 5 (Table 2) [29]. The consulted expert panel included local specialists from the fields of medicine, primary-care and community medicine.

The severity of illness of MI was described with the Thrombolysis in Myocardial Infarction (TIMI) risk score [30]. For NSTEMI it was calculated by allocating a score out of seven; four of which was related to the past medical history and three for the clinical presentation [31]. For STEMI, the score was out of maximum 14; four of which was given for the past medical history, eight for the examinations and two for presentation [32]. The higher the TIMI score, the worse the severity of the disease.

Data was entered into a pre-designed sheet in Statistical package for Social Sciences (SPSS version 20). Demographic factors and several aspects of financial burden were elaborated using descriptive statistics. The group with financial burden was defined as at least having one of the phenomena mentioned in Table 3. The association between the presence of financial burden

Table 1 Scoring method of the tool to assess the level of social support

\begin{tabular}{ll}
\hline Question & Score \\
\hline Availability of someone to call & 1 \\
Availability of someone to talk to & 1 \\
Availability of someone to encourage & 1 \\
Availability of someone to help in daily activities & 1 \\
Availability of someone to help in house keeping & 1 \\
Availability of someone to take to the doctor & 1 \\
Availability of someone to provide financial assistance & 1 \\
Availability of someone to provide a vehicle & 1 \\
Availability of someone to give information about the disease & 1 \\
Availability of help from any institution/ group & 1 \\
Total & 10 \\
\hline
\end{tabular}

Table 2 Scoring method for the tool for quantifying the health infrastructure

\begin{tabular}{lll}
\hline Domain & Scores and criteria & \\
\hline $\begin{array}{l}\text { i. Distance to the nearest } \\
\text { pharmacy }\end{array}$ & $<1 \mathrm{~km}$ & $>1 \mathrm{~km}$ \\
$\begin{array}{l}\text { ii. Distance to the nearest } \\
\text { place a doctor can be }\end{array}$ & 0.5 & 0 \\
$\begin{array}{l}\text { consulted } \\
\text { iii. Distance to the nearest }\end{array}$ & 1 & $>1 \mathrm{~km}$ \\
hospital & $<1 \mathrm{~km}$ & 0 \\
$\begin{array}{l}\text { iv. Distance to the nearest } \\
\text { hospital with specialist care }\end{array}$ & 1 & $>1 \mathrm{~km}$ \\
v. Availability of a healthcare & 1 & 0 \\
personnel for health advices/ & 1 & $>1 \mathrm{~km}$ \\
clarifications & Yes & 0 \\
vi. Ownership of vehicles & Yes & No \\
& 0.25 & 0 \\
vii. Condition of roads & Does not & No \\
& cause delays & 0 \\
& 0.25 & 0 \\
\hline
\end{tabular}

and the SDHS in categorical form was evaluated by the chi square test. The score of the SDHs which were in quantitative form and the QOL scores were nonnormally distributed when assessed by Q-Q plots and Kolmogorov-Smirnov test. Hence non-parametric tests were used in analyzing their associations. Mann Whitney $U$ test was used for analysis of associations of financial burden with numerically-measured SDHs and with QOL. The same test was used to analyze for the association between QOL and the type of MI. Spearman correlation coefficient was used to describe the association between QOL versus TIMI risk score and left ventricular ejection fraction prior to hospital discharge.

Informed written consent was obtained similar to methods used by Hofhuis et al. in 2007 [33]. Data collections were done without disturbing the patient management processes. Ethical clearance was obtained and administrative permissions were obtained prior to the initiation of data collection.

\section{Results}

The median (IQR) of the age distribution of the recruited study sample was 62.0 (54.0-70.0). Out of the recruited participants 270 either posted back the questionnaire or gave the responses over the phone with

Table 3 Financial burden experienced by the study population

\begin{tabular}{llll}
\hline Burden & Yes & No & Not mentioned \\
& N (\%) & N (\%) & N (\%) \\
\hline Had to apply for a loan & $45(15.4)$ & $209(71.3)$ & $16(13.3)$ \\
Had to sell a property & $23(7.8)$ & $222(75.8)$ & $25(16.4)$ \\
Had a potential income loss & $56(19.1)$ & $192(65.5)$ & $22(15.4)$ \\
Had to restricted other expenses & $99(33.8)$ & $154(52.6)$ & $17(13.6)$ \\
\hline
\end{tabular}


a general response rate of $80.8 \%$. The non-responders had either died following the hospital admission or could not be contacted. The analysis of the characteristics of responders and non-responders showed that the nonresponse bias is unlikely $[34,35]$.

Out of the respondents 65 were with a STEMI and 205 were with NSTEMI. The median (IQR) age was 58 (5167) years. Male to female ratio was 7:3with 186 males and 84 females. The median (IQR) TIMI score for the STEMI group was 3 (3 to 5) and for NSTEMI was 2 (2 to 4). All recruited STEMI patients were given streptokinase as the intravenous fibrinolytic therapy and NSTEMI patients received parenteral anticoagulant therapy.

Out of the responders, 139 (51.5\%) had been employed by 1 month of hospital discharge. Around $31 \%(n=85)$ of the employees stated that they had a limitation of physical activity and around $43 \%(n=115)$ had to limit the employment time due to the effects of the MI. Nearly 5\% $(n=6)$ of those who were not employed by one month had lost their previously engaged job due to the illness.

Around $43 \%(n=116)$ have stated that they had to request the financial support from a third party due to the illness. Around $86 \%(n=231)$ need to have someone to accompany him or her for any form of further medical management following hospital discharge. Out of these companions, around $60 \%$ are engaged in a daytime job and they had to limit some portion of their working time for accompanying the participant.

Table 3 summarizes the financial burden experienced by the participants in relation to four selected questions. Out of the respondents, 137 (50.7\%) had experienced at least one of the four occurrences mentioned.

The Table 4 shows that the group without financial burden has better figures for the education level, income, level of social support and the level of health infrastructure. When analyzed by the non-parametric Mann Whitney U test the latter three show a statistically significant difference between the two groups.
The SDHs mentioned in Table 5 which are gender, ethnicity and place of living do not show a statistically significant different association between the two groups.

The QOL at post-discharge 1 month, shows a significant difference between the two groups in relation to both the index value $(p=0.002)$ and the Visual Analogue Scale (VAS) value $(p<0.001)$ (Table 6$)$ of the EQ-5D-3 L QOL tool.

EQ-5D index value did not show a significant association with the TIMI risk score for the STEMI group $(p=0.075)$ nor with the NSTEMI group $(p=0.058)$. Similarly the EQ-5D VAS values too, did not show a statistically significant association between STEMI $(p=$ $0.35)$ or NSTEMI groups $(p=0.364)$. Furthermore in a subgroup analysis of approximately one fourth of the participants, the left ventricular ejection fraction prior to hospital discharge did not show a significant association with either the EQ-5D-index score $(p=0.222)$ or the EQ-5D-VAS score $(p=0.693)$. Neither the EQ-5D index score $(p=0.392)$ nor the EQ-5D-VAS $(p=0.125)$ showed a statistically significant difference between STEMI and NSTEMI groups.

\section{Discussion}

The study shows that a substantial number of MI survivors had experienced a financial burden. Furthermore, the financial burden experienced by them has a significant association with three $\mathrm{SDHs}$ and with the postdischarge QOL at one month. The Sri Lankan health financing system involves two main sources: general taxation and out-of-pocket household spending [2]. Private insurance is a supplementary-optional method. Since the uptake of insurance is weak, there is a potential for outof-pocket expenditures to be incurred by patients with MI. Higher magnitude of Out of Pocket expenditure is a major restriction in the country's path towards achieving Universal Health Coverage. It not only leads to impoverishment, but also restricts access to medical care.

Table 4 Association between financial burden and selected social determinants

\begin{tabular}{|c|c|c|c|c|}
\hline Social determinant & Financial burden category & Mean (SD) & Median (IQR) & Significance of difference $^{a}$ \\
\hline \multirow[t]{2}{*}{ Education level } & With burden & $8.09(3.91)$ & $9.00(5.00-11.00)$ & \multirow[t]{2}{*}{$p=0.184$} \\
\hline & No burden & $8.65(4.15)$ & $10.0(5.50-11.00)$ & \\
\hline \multirow[t]{2}{*}{ Income } & With burden & $2.20(1.32)$ & $2.00(1.00-3.00)$ & \multirow[t]{2}{*}{$p=0.001^{b}$} \\
\hline & No burden & $2.69(1.31)$ & $3.00(2.00-4.00)$ & \\
\hline \multirow[t]{2}{*}{ Social support } & With burden & $7.03(2.13)$ & 7.00 (6.00-9.00) & \multirow[t]{2}{*}{$p=0.002^{b}$} \\
\hline & No burden & $7.83(1.79)$ & $8.00(7.00-9.00)$ & \\
\hline \multirow[t]{2}{*}{ Health infrastructure } & With burden & $1.86(1.26)$ & $1.50(0.75-2.75)$ & \multirow[t]{2}{*}{$p<0.001^{b}$} \\
\hline & No burden & $3.28(1.04)$ & $3.25(2.50-4.13)$ & \\
\hline
\end{tabular}

${ }^{a}$ Analyzed by the Mann-Whitney $\mathrm{U}$ test

${ }^{b}$ significant at $5 \%$ level 
Table 5 Association between financial burden and selected social determinants

\begin{tabular}{|c|c|c|c|c|}
\hline \multirow[t]{2}{*}{ Selected SDH } & \multirow{2}{*}{$\begin{array}{l}\text { Yes } \\
\text { N (\%) }\end{array}$} & \multirow{2}{*}{$\begin{array}{l}\text { No } \\
\text { N (\%) }\end{array}$} & \multirow{2}{*}{$\begin{array}{l}\text { Total } \\
\text { N (\%) }\end{array}$} & \multirow{2}{*}{$\begin{array}{l}\text { Significance of } \\
\text { difference }^{a}\end{array}$} \\
\hline & & & & \\
\hline \multicolumn{5}{|l|}{ Gender } \\
\hline -Male & 98 & 85 & $183(100)$ & \multirow[t]{2}{*}{$p$ value $=0.146$} \\
\hline -Female & 36 & 46 & $82(100)$ & \\
\hline \multicolumn{5}{|l|}{ Ethnicity } \\
\hline -Sinhala & 117 & 100 & $217(100)$ & \multirow[t]{2}{*}{$p$ value $=0.068$} \\
\hline -Others & 18 & 28 & $46(100)$ & \\
\hline \multicolumn{5}{|l|}{ Area } \\
\hline -Urban & 79 & 70 & $149(100)$ & \multirow[t]{2}{*}{$p$ value $=0.369$} \\
\hline -Rural & 35 & 40 & $75(100)$ & \\
\hline
\end{tabular}

The financial burden summarized in Table 3 needs to be interpreted while recognizing the presence of comorbid conditions. Some participants, who were previously unaware about the presence of co-morbidities, had them detected during the current admission. Managing these co-morbidities would have worsened the financial burden. For example if a drug becomes temporarily outof-stock in the hospital pharmacy, the patient would need to purchase it from a private pharmacy.

Following one month of the hospital discharge, 51.5\% mentioned that they were working. A quicker return to work may have been necessitated by the economic burden as documented in global literature too [18]. The employed participants had to face some limitations in activities and had to compromise some aspects of the lifestyle comparable to the global literature [23]. The financial restraints are major concerns of the survivors of chronic illnesses as documented in the global literature $[18,20,21,23,36]$. Similarly the present study shows that in a lower-middle-income country these concerns remain the same. These results indicate that the economic consequences are multi-faceted and have a negative impact on the lifestyles. These issues are not usually captured by the routine health information systems.

The associations between SDHs in Tables 5 and 6 suggest that the gender $(p=0.146)$, ethnicity $(p=0.068)$, highest education $(p=0.184)$ and the area of residence $(p=0.369)$ are not significantly associated with the financial burden. Hence the findings can be generalized irrespective of the gender, ethnicity or place of living. The influence of income $(p=0.001)$, social support $(p=0.002)$ and the health infrastructure $(p<0.001)$ were noted as statistically significant. This fact strengthens the available scientific literature which shows the association between financial burden versus the SDHs $[13,14,16]$. When these SDHs were unfavorable, the financial burden was seemingly worse.

When the pre-event income is low, the presence of a financial burden following the MI is more likely. This would have been resulted by the lack of savings. A better level of social support minimizes the risk of the occurrence of financial burden. This may not be only due to the mere financial inputs and would be due to the other factors like knowledge sharing as well. Similarly a better health infrastructure would have a protective effect preventing the MI survivors going into financial burden.

The EQ-5D-3 L QOL tool has been developed by EuroQol group. It consist of EQ-5D descriptive system as well as EQ-5D VAS [37, 38]. It focuses on the day of the measurement of the QOL. It has been validated in previous studies in Sri Lanka [29, 39]. The minimum time taken for the completion and the relative simplicity make it a suitable QOL tool to be used to measure the one month post-hospital discharge QOL of MI survivors. The results revealed a significantly lower QOL in relation to both components (index score and VAS) among the group which was with a financial burden (Table 6). It points towards the importance of financial interventions in improving the QOL of MI survivors.

MI has significant negative consequences for the sufferers in relation to physical, emotional and social dimensions. Globally it is shown that the QOL of the coronary patients anyhow is significantly impaired following the illness [7, 40-42]. Measuring QOL of cardiac patients provide the opportunity of reflecting the success of the management in the patient's point of view [43].

This is an era that the whole world is concerned about the equity issues in relation to health financing. Different income inequality measures are available in the literature such as; Gini coefficient, Atkinson index, generalizedentrophy index, Kakwani index [44-46]. It is timely that

Table 6 Association between financial burden and the quality of life

\begin{tabular}{lllll}
\hline QOL & Financial burden category & Mean (SD) & Median (IQR) & Significance of difference $^{\mathrm{a}}$ \\
\hline EQ-5D index value & With burden & $0.486(0.38)$ & $0.516(0.49-0.73)$ & $p=0.002^{\mathrm{b}}$ \\
& No burden & $0.671(0.19)$ & $0.585(0.52-0.85)$ & \\
EQ-5D VAS value & With burden & $60.97(21.46)$ & $60.0(50.00-77.50)$ & $p<0.001^{\mathrm{b}}$ \\
& No burden & $71.56(15.39)$ & $70.0(60.00-80.00)$ & \\
\hline
\end{tabular}

${ }^{\mathrm{a} A n a l y z e d}$ by Mann Whiney $\mathrm{U}$ test

${ }^{b}$ significant at $5 \%$ level 
lower-middle-income countries like Sri Lanka encourage more scientific literature on these regards. This further provides evidence on actual necessity of healtheconomic reforms like social insurance systems and guided donations.

There were several limitations of the study. The financial burden was in categorical form and the quantification with a monetary value was not done. It was the best possible option as exploring quantification evidence could not be possible especially when the respondent is not exposed to a face-to-face interview. Secondly the out-of-pocket expenditure in some patients may be due to the temporary scarcities of certain medicines in particular hospitals requiring the patient to purchase them. This should be considered in interpreting the results. Thirdly the present study only recruited the medicallymanaged survivors of MI. This was due to the fact that at the time of data collection, there was no uniform financial-supporting system for all the MI patients who were managed with invasive interventions. Hence the exclusion of these patients enabled the applicability of the findings for the medically-managed patients in relation to the financial-burden, even if the policies related to surgical interventions change from time to time. However, since the mode of management may influence the post-discharge QOL, the findings of the present study on the QOL too, should not be generalized to the survivors of MI who underwent an invasive intervention. Since the study did not have an objective of describing any incidence-related parameter, the total participants who were screened for eligibility was not documented. Finally the left ventricular ejection fraction analysis was done for only one fourth of the respondents. This should be concerned in interpreting its associations.

\section{Conclusions}

The survivors of MI who are medically-managed, have to face financial burden due to the out-of-pocket expenditure as well as due to the limitations the illness imposes on their occupations. This burden occurs irrespective of the gender, ethnicity, education and the place of residence. It is influenced significantly by the income, level of social support and the level of health infrastructure. The financial burden is influencing the post-discharge 1 month QOL of the medically-managed MI survivors. More research should be encouraged in these regards and the evidences must be coupled with health reforms to mitigate the impact of financial burden due to illness.

\section{Abbreviations}

CABG: Coronary Artery Bypass Graft; CHE: Catastrophic Health Expenditure; CSDH: Commission on Social Determinants of Health; EQ-5D-3 L: EuroQolfive-dimensional-3-level questionnaire; Ml: myocardial infarction; NCDs: Non Communicable Diseases; NSTEMI: Non- ST elevation myocardial infarction;
PCI: Percutaneous Coronary Intervention; QOL: quality of life; SDHs: social determinants; STEMI: ST elevation myocardial infarction; TIMI risk score: Thrombolysis in Myocardial Infarction (TIMI) risk score; VAS: Visual Analogue Scale

\section{Acknowledgements \\ Authors like to acknowledge the EuroQOL group for providing the Sinhalaese translation of the EQ-5D-3 L questionnaire (Registration ID:6554) and the UK-TTO dataset free of charge.}

Funding

The study was self-funded and was not funded by a third party.

\section{Availability of data and materials}

The datasets used and/or analyzed during the current study are available from the corresponding author on reasonable request.

\section{Authors' contributions}

All authors were involved in the planning of the research study. PKBM was the principal investigator and involved in getting ethics permissions, data collection, data analysis and writing of the manuscript. MWG, SJ, SMA and DSVM were involved in data analysis, data interpretation and writing of the manuscript. SKP and UADW were involved in data collection, data entering, interpretation of data and in writing the manuscript. All authors went through the final manuscript. All authors read and approved the final manuscript.

Ethics approval and consent to participate

Ethics approval was obtained from the Ethics Review Committee of Sri Lanka Medical Association prior to the data collection (Reference number: ERC/14019 approval was given on 27th August 2014). Informed written consent was obtained from the participants.

\section{Consent for publication}

Not applicable.

\section{Competing interests}

The authors declare that they have no competing interests.

\section{Publisher's Note}

Springer Nature remains neutral with regard to jurisdictional claims in published maps and institutional affiliations.

\section{Author details}

${ }^{1}$ Office of Regional Director of Health Services, Colombo, Sri Lanka. ${ }^{2}$ Department of Community Medicine, Faculty of Medicine, University of Colombo, Colombo, Sri Lanka. ${ }^{3}$ Department of Clinical Medicine, Faculty of Medicine, University of Colombo, Colombo, Sri Lanka. ${ }^{4}$ Non Communicable Disease Unit, Ministry of Health, Colombo, Sri Lanka. ${ }^{5}$ Post Graduate Institute of Medicine, University of Colombo, Colombo, Sri Lanka. ${ }^{6}$ Cardiology Unit, National Hospital Sri Lanka, Colombo, Sri Lanka.

Received: 9 August 2017 Accepted: 13 September 2017

Published online: 19 September 2017

References

1. WHO. Global Status Report on Non Communicable Diseases. Geneva: World Health Organization; 2014. http://apps.who.int/iris/bitstream/10665/148114/ 1/9789241564854_eng.pdf

2. Engelgau M, Okamoto K, Navaratne KV, Gopalan S. Prevention and Control of Selected Chronic NCDs in Sri Lanka: Policy Options and Action. Health, Nutrition and Population Family. Human Development Network. Washington: World Bank; 2010. http://hdl.handle.net/10986/13607.

3. Joseph N. Assessment of Economic Impact Among In-Patients with NonCommunicable Diseases in a Private Tertiary Care Hospital in Southern India. J Clin Diagn Res. 2016; doi:10.7860/JCDR/2016/19426.8059.

4. Moran AE, Forouzanfar MH, Roth GA, et al. The Global Burden of Ischemic Heart Disease in 1990 and 2010: The Global Burden of Disease 2010 Study. Circulation. 2014;129(14):1493-501. doi:10.1161/CIRCULATIONAHA.113.004046.

5. Sanchis-Gomar F, Perez-Quilis C, Leischik R, Lucia A. Epidemiology of coronary heart disease and acute coronary syndrome. Ann Transl Med. 2016;4(13):256. 10.21037/atm.2016.06.33. 
6. Schlatter RP, Hirakata VN, Polanczyk CA. Estimating the direct costs of ischemic heart disease: evidence from a teaching hospital in BRAZIL, a retrospective cohort study. BMC Cardiovasc Disord. 2017;17(1):180. doi:10.1186/s12872-017-0615-1.

7. Mahesh PKB, Gunathunga MW, Jayasinghe S, Arnold SM, Haniffa R, De Silva AP. Pre-event quality of life and its influence on the post-event quality of life among patients with ST elevation and non-ST elevation myocardial infarctions of a premier province of Sri Lanka. Health Qual Life Outcomes. 2017:15(1):154. doi:10.1186/s12955-017-0730-9.

8. Medagama A, Bandara R, De Silva C, Galgomuwa MP. Management of acute coronary syndromes in a developing country; time for a paradigm shift? an observational study. BMC Cardiovasc Disord. 2015;15(1):133. doi:10.1186/ s12872-015-0125-y.

9. Anderson JL, Morrow DA. Acute Myocardial Infarction. N Engl J Med. 2017; 376(21):2053-64. doi:10.1056/NEJMra1606915.

10. Pankaj SN, Kanchan M. Economic Effect of Coronary Heart Disease on Households - A study in Mumbai. Int J Med Public Heal. 2016;6(4):184-8. doi:10.5530/ijmedph.2016.4.8.

11. Dhaliwal KK, King-Shier K, Manns BJ, Hemmelgarn BR, Stone JA, Campbell DJT. Exploring the impact of financial barriers on secondary prevention of heart disease. BMC Cardiovasc Disord. 2017;17(1):61. doi: 10.1186/s12872-017-0495-4.

12. Campbell DJT, Manns BJ, Weaver RG, Hemmelgarn BR, King-Shier KM, Sanmartin C. Financial barriers and adverse clinical outcomes among patients with cardiovascular-related chronic diseases: a cohort study. BMC Med. 2017;15(1):33. doi:10.1186/s12916-017-0788-6.

13. Wang Q, Liu H, Lu ZX, Luo Q, Liu JA. Role of the new rural cooperative medical system in alleviating catastrophic medical payments for hypertension, stroke and coronary heart disease in poor rural areas of China. BMC Public Health. 2014;14(1):907. doi:10.1186/1471-2458-14-907.

14. Daivadanam M, Thankappan KR, Sarma PS, Harikrishnan S. Catastrophic health expenditure \& coping strategies associated with acute coronary syndrome in Kerala, India. Indian J Med Res. 2012;136(4):585-92. http://www.ncbi.nlm.nih. gov/pmc/articles/PMC3516025/

15. CSDH. Closing the gap in a generation, Closing Gap Gener Heal Equity Through Action Soc Determ Heal Final Rep Comm Soc Determ Heal; 2008. p. 246. doi:10.1080/17441692.2010.514617.

16. Krumeich A, Meershoek A. Health in global context; beyond the social determinants of health? Glob Health Action. 2014;7(SUPP.1) doi:10.3402/ gha.v7.23506.

17. Jaspers $L$, Colpani V, Chaker L, et al. The global impact of non-communicable diseases on households and impoverishment: a systematic review. Eur J Epidemiol. 2015;30(3):163-88. doi:10.1007/s10654-014-9983-3.

18. Herridge MS, Cheung AM, Tansey CM, et al. One-year outcomes in survivors of the acute respiratory distress syndrome. N Engl J Med. 2003;348(8):68393. doi:10.1056/NEJMoa022450.

19. Griffiths JA, Barber VS, Cuthbertson BH, Young JD. A national survey of intensive care follow-up clinics. Anaesthesia. 2006;61(10):950-5. doi:10.1111/ j.1365-2044.2006.04792.x.

20. Swoboda SM, Lipsett PA. Impact of a prolonged surgical critical illness on patients' families. Am J Crit Care. 2002;11(5):459-66.

21. Covinsky KE, Goldman L, Cook EF, et al. The impact of serious illness on patients' families. SUPPORT Investigators. Study to Understand Prognoses and Preferences for Outcomes and Risks of Treatment. JAMA. 1994;272(23): 1839-44. doi:10.1001/jama.272.23.1839.

22. Campbell DJT, King-Shier K, Hemmelgarn BR, et al. Self-reported financial barriers to care among patients with cardiovascularrelated chronic conditions. Heal Rep. 2014;25(5):3-12.

23. Griffiths J, Hatch RA, Bishop J, et al. An exploration of social and economic outcome and associated health-related quality of life after critical illness in general intensive care unit survivors: a 12-month follow-up study. Crit Care. 2013;17(3):R100. doi:10.1186/cc12745.

24. Mendis S, Thygesen K, Kuulasmaa K, et al. World Health Organization definition of myocardial infarction: 2008-09 revision. Int J Epidemiol. 2011;40(1):139-46. doi:10.1093/ije/dyq165.

25. Steg PG, James SK, Atar D, et al. ESC Guidelines for the management of acute myocardial infarction in patients presenting with ST-segment elevation: The Task Force on the management of ST-segment elevation acute myocardial infarction of the European Society of Cardiology (ESC). Eur Heart J. 2012;33(20):2569-619. doi:10.1093/eurheartj/ehs215.
26. Suresh K, Chandrashekara S. Sample size estimation and power analysis for clinical research studies. J Hum Reprod Sci. 2012;5(1):7. doi:10.4103/09741208.97779

27. Department of Census and Statistics. Sri Lanka Census on Population and Housing. 2012. http://www.statistics.gov.Ik/PopHouSat/CPH2011/index. php?fileName=FinalPopulation\&gp=Activities\&tpl=3.

28. Mallawarachchi DSV. Quality of Life of Stroke Patients Presenting to Selected Hospitals in the Colombo District and the Possibility of Common Mental Disorders among the Principal Informal Caregivers. MD thesis in Community Medicine. Colombo: Post Graduate Institute of Medicine; 2007.

29. Mahesh PKB, Gunathunga MW, Jayasinghe S. Influence of social determinants on the disease-outcome, financial burden and quality of life after a critical illness due to chronic Non Communicable Diseases, among patients treated at government hospitals in the Western province of Sri Lanka. MD thesis in Community Medicine. Colombo: Post Graduate Institute of Medicine; 2015

30. Hudzik B, Lekston A, Gasior M. Risk Prediction in Acute Myocardial Infarction. J Am Coll Cardiol. 2016;68(25):2918-9. doi:10.1016/j.jacc.2016.08.078.

31. Numasawa $Y$, Kohsaka S, Miyata H, et al. Use of Thrombolysis in Myocardial Infarction Risk Score to predict bleeding complications in patients with unstable angina and non-ST elevation myocardial infarction undergoing percutaneous coronary intervention. Cardiovasc Interv Ther. 2013;28(3):242-9. doi:10.1007/s12928-013-0162-3.

32. Silveira DS, Jaeger CP, Hatschbach L, Manenti ERF. Validation of TIMI Risk Score for STEMI. Int J Cardiovasc Sci. 2016; doi:10.5935/2359-4802.20160034.

33. Hofhuis JG, Spronk PE, van Stel HF, Schrijvers AJ, Bakker J. Quality of life before intensive care unit admission is a predictor of survival. Crit Care. 2007;11(4):R78. doi:10.1186/cc5970.

34. Wittwer R, Hubrich S. Nonresponse in Household Surveys: A Survey of Nonrespondents from the Repeated Cross-sectional Study "Mobility in Cities - SrV" in Germany. Transp Res Procedia. 2015;11:66-84. doi:10.1016/ j.trpro.2015.12.007.

35. Johnson TP. Response Rates and Nonresponse Errors in Surveys. JAMA. 2012;307(17):1805. doi:10.1001/jama.2012.3532.

36. Panos RJ, Krywkowski-Mohn SM, Sherman SN, Lach LA. Patient Reported Determinants of Health: A Qualitative Analysis of Veterans with Chronic Obstructive Pulmonary Disease. COPD. 2013;10:333-47. doi:10.3109/ 15412555.2012.752805.

37. Reenen M, Oppe M. EQ-5D-3L User Guide. EuroQol Research Foundation: Netherland; 2015

38. Gusi N, Olivares PR, Rajendram R. The EQ-5D Health-Related Quality of Life Questionnaire. In: Handbook of Disease Burdens and Quality of Life Measures. New York: Springer; 2010. p. 87-99. doi:10.1007/978-0-387-78665-0_5.

39. Kularatna S, Whitty JA, Johnson NW, Jayasinghe R, Scuffham PA. EQ-5D-3L Derived Population Norms for Health Related Quality of Life in Sri Lanka. PLoS One. 2014:9(11):e108434. doi:10.1371/journal.pone.0108434.

40. Duenas M, Salazar A, Ojeda B, Failde I. Health Related Quality of Life in Coronary Patients. In: Recent Advances in Cardiovascular Risk Factors. Prof. Mehnaz Atiq (Ed.), InTech. 2012. doi:10.5772/31903.

41. Höfer S, Doering S, Rumpold G, Oldridge N, Benzer W. Determinants of health-related quality of life in patients with coronary artery disease. Eur J Cardiovasc Prev Rehabil. 2006;13(3):398-406. http://www.ncbi.nlm.nih.gov/ pubmed/16926670

42. Failde II, Soto MM. Changes in health related quality of life 3 months after an acute coronary syndrome. BMC Public Health. 2006;6(1):18. doi:10.1186/ 1471-2458-6-18.

43. Fayers PM, Machin D. Quality of Life: The Assessment, Analysis and Interpretation of Patient-Reported Outcomes: Second Edition. ISBN 9780470024515. Chichester: Wiley; 2007.

44. Kondo N, Sembajwe G, Kawachi I, van Dam RM, Subramanian SV, Yamagata Z. Income inequality, mortality, and self rated health: meta-analysis of multilevel studies. BMJ. 2009;339:b4471. doi:10.1136/bmj.b4471.

45. De Maio FG. Income inequality measures. J Epidemiol Community Health. 2007;61(10):849-52. doi:10.1136/jech.2006.052969.

46. Haghparast-Bidgoli H, Pulkki-Brännström A-M, Lafort $Y$, et al. Inequity in costs of seeking sexual and reproductive health services in India and Kenya. Int J Equity Health. 2015;14(1):84. doi:10.1186/s12939-015-0216-5. 